\title{
Prismatic Adaptation Changes Visuospatial Representation in the Inferior Parietal Lobule
}

\author{
DSonia Crottaz-Herbette, ${ }^{1}$ Eleonora Fornari, ${ }^{2}$ and Stephanie Clarke ${ }^{1}$ \\ ${ }^{1}$ Neuropsychology and Neurorehabilitation Service, Centre Hospitalier Universitaire Vaudois, and University of Lausanne, 1011 Lausanne, Switzerland, and \\ ${ }^{2}$ Centre d'Imagerie Biomédicale, Department of Radiology, Centre Hospitalier Universitaire Vaudois, and University of Lausanne, 1011 Lausanne, \\ Switzerland
}

Prismatic adaptation has been shown to induce a realignment of visuoproprioceptive representations and to involve parietocerebellar networks. We have investigated in humans how far other types of functions known to involve the parietal cortex are influenced by a brief exposure to prismatic adaptation. Normal subjects underwent an fMRI evaluation before and after a brief session of prismatic adaptation using rightward deviating prisms for one group or after an equivalent session using plain glasses for the other group. Activation patterns to three tasks were analyzed: (1) visual detection; (2) visuospatial short-term memory; and (3) verbal short-term memory. The prismatic adaptation-related changes were found bilaterally in the inferior parietal lobule when prisms, but not plain glasses, were used. This effect was driven by selective changes during the visual detection task: an increase in neural activity was induced on the left and a decrease on the right parietal side after prismatic adaptation. Comparison of activation patterns after prismatic adaptation on the visual detection task demonstrated a significant increase of the ipsilateral field representation in the left inferior parietal lobule and a significant decrease in the right inferior parietal lobule. In conclusion, a brief exposure to prismatic adaptation modulates differently left and right parietal activation during visual detection but not during short-term memory. Furthermore, the visuospatial representation within the inferior parietal lobule changes, with a decrease of the ipsilateral hemifield representation on the right and increase on the left side, suggesting thus a left hemispheric dominance.

Key words: fMRI; inferior parietal; prismatic adaptation; visual detection

\section{Introduction}

Prismatic lenses, which deviate the visual field, unilaterally induce during the first trials pointing errors that are followed by a phase of correct pointing (Redding and Wallace, 1993; Rossetti et al., 1998; Redding et al., 2005). The aftereffect (i.e., pointing errors to the opposite direction after prisms are removed, reflecting the prism-induced sensorimotor realignment) (Weiner et al., 1983) was shown to last up to $24 \mathrm{~h}$ for open loop pointing and up to a week for straight ahead pointing (Hatada et al., 2006a).

Several studies investigated neural processes underlying ongoing prismatic adaptation (PA) and reported activation within the parietotemporal cortex and the cerebellum, suggesting a visual and proprioceptive spatial realignment (Clower et al., 1996; Danckert et al., 2008; Luauté et al., 2009; Chapman et al., 2010), similar to that observed in other types of visuomotor coordinate

\footnotetext{
Received July 25, 2013; revised June 12, 2014; accepted July 10, 2014.

Author contributions: S.C.-H. and S.C. designed research; S.C.-H. and E.F. performed research; S.C.-H. and E.F. analyzed data; S.C.-H. and S.C. wrote the paper.

The work was supported by the Swiss National Science Foundation Marie-Heim-Vögtlin fellowship FNS PMPDP3_129028 to S.C.-H., Swiss National Science Foundation Grant FNS 320030B-141177 to S.C., the Biaggi Foundation to S.C.-H., and the Centre d'Imagerie BioMédicale of the University of Lausanne.

The authors declare no competing financial interests.

Correspondence should be addressed to Dr. Sonia Crottaz-Herbette, Neuropsychology and Neurorehabilitation Service, Lausanne University Hospital (Centre Hospitalier Universitaire Vaudois), Av. Pierre-Decker 5, 1011 Lausanne, Switzerland. E-mail: sonia.crottaz-herbette@chuv.ch.

DOI:10.1523/JNEUROSCI.3184-13.2014

Copyright $\odot 2014$ the authors $\quad 0270-6474 / 14 / 3411803-09 \$ 15.00 / 0$
}

transformations (Inoue et al., 2000; Grefkes et al., 2004; Krakauer et al., 2004; Diedrichsen et al., 2005; Graydon et al., 2005).

In normal subjects, behavioral effects after PA were reported mostly after adaptation using leftward deviating prisms on line bisection (Colent et al., 2000; Berberovic and Mattingley, 2003; Michel et al., 2003); straight ahead pointing without vision, visual straight ahead judgment, and open loop pointing (Hatada et al., 2006b; Sarri et al., 2008); passive proprioceptive midsaggital judgment (Hatada et al., 2006a); haptic and visual representation of central space (Girardi et al., 2004); and reorienting attention from an invalid cue (Striemer et al., 2006). Interestingly, several studies have shown that, in normal subjects, such effects are larger after adaptation using leftward than rightward prisms (Loftus et al., 2008; Nicholls et al., 2008; Bultitude et al., 2013; Schintu et al., 2014; however, see Berberovic and Mattingley, 2003; Striemer et al., 2006).

In neglect patients with right-hemispheric lesions, changes after rightward PA were reported to be of similar or larger amplitude than in normal subjects, to last longer (Rossetti et al., 1998; Sarri et al., 2008) and to decrease neglect symptoms in line bisection, cancellation and copy tasks, mental imagery, ocular scanning, postural imbalance, and auditory and tactile extinction (Rode et al., 2001; Tilikete et al., 2001; McIntosh et al., 2002; Dijkerman et al., 2003; Ferber et al., 2003; Maravita et al., 2003; Jacquin-Courtois et al., 2010), and in some cases perceptual judgment (Ferber et al., 2003; Sarri et al., 2006, 2011). 
One remaining question concerns the neural modulations after rightward deviating PA underlying other types of functions known to involve the parietal cortex in normal subjects. We have investigated this question by comparing activation patterns yielded by the following: (1) visual detection; (2) visual shortterm memory (STM); and (3) verbal STM before and after a session of PA in normal subjects using rightward deviating prisms inducing leftward aftereffects. Rightward deviating prisms were chosen to have an adaptation similar to the adaptation used in the treatment of left visual neglect. The nonspecific effects of visual pointing were controlled for in a second experiment that used plain glasses, instead of prisms, in a different group of normal subjects.

\section{Materials and Methods}

Participants. Twenty-eight subjects participated in this study, of which 14 (7 men, mean age 26.0 years, SD 5.0 years) in PA and 14 ( 7 men, mean age 25.8 years, SD 4.8 years) in the control group (Ctl). All subjects were right handed (Oldfield, 1971) and had a normal or corrected-to-normal vision and no neurological or psychiatric illness. All participants gave written informed consent according to procedures approved by the Ethics Committee of the Faculty of Biology and Medicine, University of Lausanne.

Experimental design. Both the PA and the Ctl groups followed the same procedure comprising two identical MRI blocs, which were separated by an intervention using visuomotor adaptation. This intervention involved pointing to visual targets wearing either rightward deviating prisms or plain glasses. Each MRI block consisted of anatomical sequences and event-related fMRI acquisitions during three tasks: (1) visual detection; (2) visuospatial STM; and (3) verbal STM. The order of the tasks was counterbalanced across participants. During all tasks, central fixation was maintained; a computer interface was used and subjects responded by pressing a button with their right hand. The tasks were programmed using the software E-Prime (Psychology Software Tools).

Visuomotor adaptation. The visuomotor adaptation was performed outside the scanner and consisted of pointing with the right index finger to visual targets presented $14^{\circ}$ to the left or to the right of the midsagittal plane. The subject's head was immobilized in a headrest, and two-thirds of the pointing trajectories were hidden from her view. The visuomotor adaptation involved 3 min of pointing movements with the right hand $(\sim 150$ movements). Participants in the PA group wore during visuomotor adaptation prisms (www.optiquepeter.com) that deviated their visual field $10^{\circ}$ to the right (Rossetti et al., 1998; Redding et al., 2005; Pisella et al., 2006; Rode et al., 2006; Jacquin-Courtois et al., 2013). After a few numbers of trials showing initial error in the direction to the prisms deviation, all participants pointed correctly to the targets. The aftereffect was assessed immediately after the prisms were removed; the participants were asked to look (without the prisms) at the visual target, then to close their eyes and to reach with their right index finger for the visual target. The same procedure was used twice for the left target and twice for the right target in a random order. For each subject and each target position, we put a mark on the table where the participant pointed and we measured, in millimeters, the deviation between the pointing and the actual target, with positive values representing a deviation to the left of the targets and negative values a deviation to the right of the targets. We averaged together the two pointings for each target locations. A mixeddesign analysis of variance (ANOVA) with group (PA, Ctl) as betweensubjects factor and side of target (left, right) as within-subjects factor was conducted on these data.

To examine the duration of the aftereffect, a separate group of 6 subjects underwent an experiment that included PA followed by the three tasks that were used during our fMRI acquisitions. The accuracy of pointing was measured before $\mathrm{PA}\left(\mathrm{T}_{0}=\right.$ baseline), immediately after PA $\left(\mathrm{T}_{1}\right)$ and then after each of the three tasks $\left(\mathrm{T}_{2}, \mathrm{~T}_{3}\right.$, and $\mathrm{T}_{4}$, respectively), using open-loop pointings, 2 on the left and 2 on the right target (same method as in the main study). The order between the three tasks was counterbalanced across our 6 subjects. The pointing error at $\mathrm{T}_{0}, \mathrm{~T}_{1}, \mathrm{~T}_{2}$, $\mathrm{T}_{3}$, and $\mathrm{T}_{4}$ was $12 \mathrm{~mm}$ (SEM $\left.6 \mathrm{~mm}\right), 105 \mathrm{~mm}(14 \mathrm{~mm}), 81 \mathrm{~mm}(11 \mathrm{~mm})$,
$63 \mathrm{~mm}(9 \mathrm{~mm})$, and $60 \mathrm{~mm}(12 \mathrm{~mm})$ at the left target and $8 \mathrm{~mm}(5 \mathrm{~mm})$, $91 \mathrm{~mm}(11 \mathrm{~mm}), 58 \mathrm{~mm}(11 \mathrm{~mm}), 49 \mathrm{~mm}(7 \mathrm{~mm})$, and $45 \mathrm{~mm}(10 \mathrm{~mm})$ at the right target. $t$ tests (Bonferroni corrected for each target at $p<$ $0.0125(0.05$ divided by 4$)$ ) compared the pointing errors at $\mathrm{T}_{1}, \mathrm{~T}_{2}, \mathrm{~T}_{3}$, and $\mathrm{T}_{4}$ to the pointing error at $\mathrm{T}_{0}$ and confirmed larger pointing error at $\mathrm{T}_{1}, \mathrm{~T}_{2}, \mathrm{~T}_{3}$, and $\mathrm{T}_{4}$ compared with $\mathrm{T}_{0}$ both for the left and right targets (left target: $\mathrm{T}_{1}: \mathrm{T}_{0} p<0.0004 ; \mathrm{T}_{2}: \mathrm{T}_{0} p<0.0002 ; \mathrm{T}_{3}: \mathrm{T}_{0} p<0.0001 ; \mathrm{T}_{4}: \mathrm{T}_{0} p<$ 0.0001 and right target: $\mathrm{T}_{1}: \mathrm{T}_{0} p<0.0002 ; \mathrm{T}_{2}: \mathrm{T}_{0} p<0.0003 ; \mathrm{T}_{3}: \mathrm{T}_{0} p<$ $\left.0.0003 ; \mathrm{T}_{4}: \mathrm{T}_{0} p<0.010\right)$. These analyses thus confirmed the persistence of the aftereffect throughout the post-PA fMRI session.

Visual detection task. Participants were asked to press the response button when they detected a visual stimuli, which was a large white star on black background, presented for $500 \mathrm{~ms}$ in three different locations: in the midsagittal plane, at $20^{\circ}$ to the right or $20^{\circ}$ to the left. The stimuli locations were randomized, and each of them was presented 20 times. The jitter of interevent intervals was up to $20 \mathrm{~s}$ with a step of $1 \mathrm{~s}$. The task lasted 6 min $44 \mathrm{~s}$.

Visuospatial STM task. The visuospatial STM task used a delayed match-to-sample design (Malhotra et al., 2004, 2005). During the first phase, five black circles with white borders were aligned vertically on a black background in the midsagittal plane; they were displayed for 500 $\mathrm{ms}$. Then three of the black circles turned white successively, for $630 \mathrm{~ms}$ each, and participants were to memorize their location. During a delay phase, a red cross appeared for $3.360 \mathrm{~s}$ in the middle of the screen followed by the five black circles for $300 \mathrm{~ms}$. Finally, during the last phase, the initial five black circles reappeared and one of them turned red during $1.5 \mathrm{~s}$. The participant had to press the button if the red circle was in a location where a white circle appeared during the first part (match event) and did not have to press any button if it appeared at a different location (no match event). In the last phase, the trials were equally distributed between match and no-match events ( 21 events in each case). Each event, including the three phases, lasted $\sim 7.550 \mathrm{~s}$. The jitter of interevent intervals was up to $20 \mathrm{~s}$ with a step of $1 \mathrm{~s}$. A total of 42 events were presented, the sequence lasted $8 \mathrm{~min} 4 \mathrm{~s}$

Verbal STM task. The verbal STM task used the same delayed matchto-sample design as the visuospatial memory task and was close to that used in a previous study (Chang et al., 2007). During the first phase, three numbers (between 1 and 5; white on black background) were presented consecutively in the middle of the screen, then a red cross appeared during a delay phase, and finally a number in red was presented and the participant had to press the button if the red number was among the three numbers presented during the first phase (match event) and did not have to press any button if it did not (no match event). The timing of the stimuli was the same as the one described for the visuospatial STM task. In the last phase, the trials were equally distributed between match and no-match events (21 trails in each case).

Data acquisition. MRI and event-related fMRI acquisitions were conducted on a 3T Siemens Magnetom Trio scanner with a 32-channel head-coil at the Lemanic Biomedical Imaging Center in the Centre Hospitalier Universitaire Vaudois, Lausanne. Functional MR images were acquired with an single-shot echo planar imaging gradient echo sequence (repetition time $=2 \mathrm{~s}$; flip angle $=90^{\circ}$; echo time $=30 \mathrm{~ms}$; number of slices $=32$; voxel size $=3 \times 3 \times 3 \mathrm{~mm} ; 10 \%$ gap). The 32 slices were acquired in a sequential ascending order and covered the whole head volume in the AC-PC plane. A high-resolution T1-weighted 3D gradient-echo sequence was acquired for each participant (160 slices, voxel size $=1 \times 1 \times 1 \mathrm{~mm}$ ). To prevent head movements in the coil, we put padding around the participant's head.

Data analysis. For all task-related behavioral performances (reaction time and number of correct responses), data were analyzed with a mixeddesign ANOVA with group (PA, Ctl) as between-subjects factor, and task (visual detection, visuospatial STM, verbal STM) and session (preintervention, postintervention) as within-subjects factors.

Imaging data were processed using Statistical Parametric Mapping (SPM8, Wellcome Department of Cognitive Neurology, London). Motion correction of the functional acquisitions was performed by applying a 6 parameter rigid-body transformation minimizing the difference between each image and the first scan. These realigned functional acquisitions were coregistered with the participant's anatomic image then 
Table 1. Average accuracy (mean \pm SEM) and average reaction times for the visual detection task and the visuospatial and verbal STM tasks for both sessions (Session 1 and Session 2, respectively)

\begin{tabular}{|c|c|c|c|c|c|c|}
\hline & \multicolumn{2}{|c|}{ Visual detection } & \multicolumn{2}{|c|}{ Visuospatial STM } & \multicolumn{2}{|l|}{ Verbal STM } \\
\hline & Session 1 & Session 2 & Session 1 & Session 2 & Session 1 & Session 2 \\
\hline \multicolumn{7}{|l|}{ Accuracy (\%) } \\
\hline PA group & $98 \pm 0.56$ & $99 \pm 0.30$ & $99 \pm 0.32$ & $97 \pm 1.08$ & $99 \pm 0.59$ & $97 \pm 1.35$ \\
\hline Ctl group (plain glasses) & $100 \pm 0.11$ & $99 \pm 0.55$ & $95 \pm 2.27$ & $100 \pm 0.00$ & $97 \pm 1.62$ & $97 \pm 1.30$ \\
\hline \multicolumn{7}{|l|}{ Reaction time (ms) } \\
\hline PA group & $404 \pm 10$ & $418 \pm 13$ & $566 \pm 13$ & $529 \pm 12$ & $645 \pm 17$ & $644 \pm 14$ \\
\hline Ctl group (plain glasses) & $367 \pm 6$ & $394 \pm 9$ & $597 \pm 24$ & $571 \pm 22$ & $642 \pm 22$ & $659 \pm 25$ \\
\hline
\end{tabular}
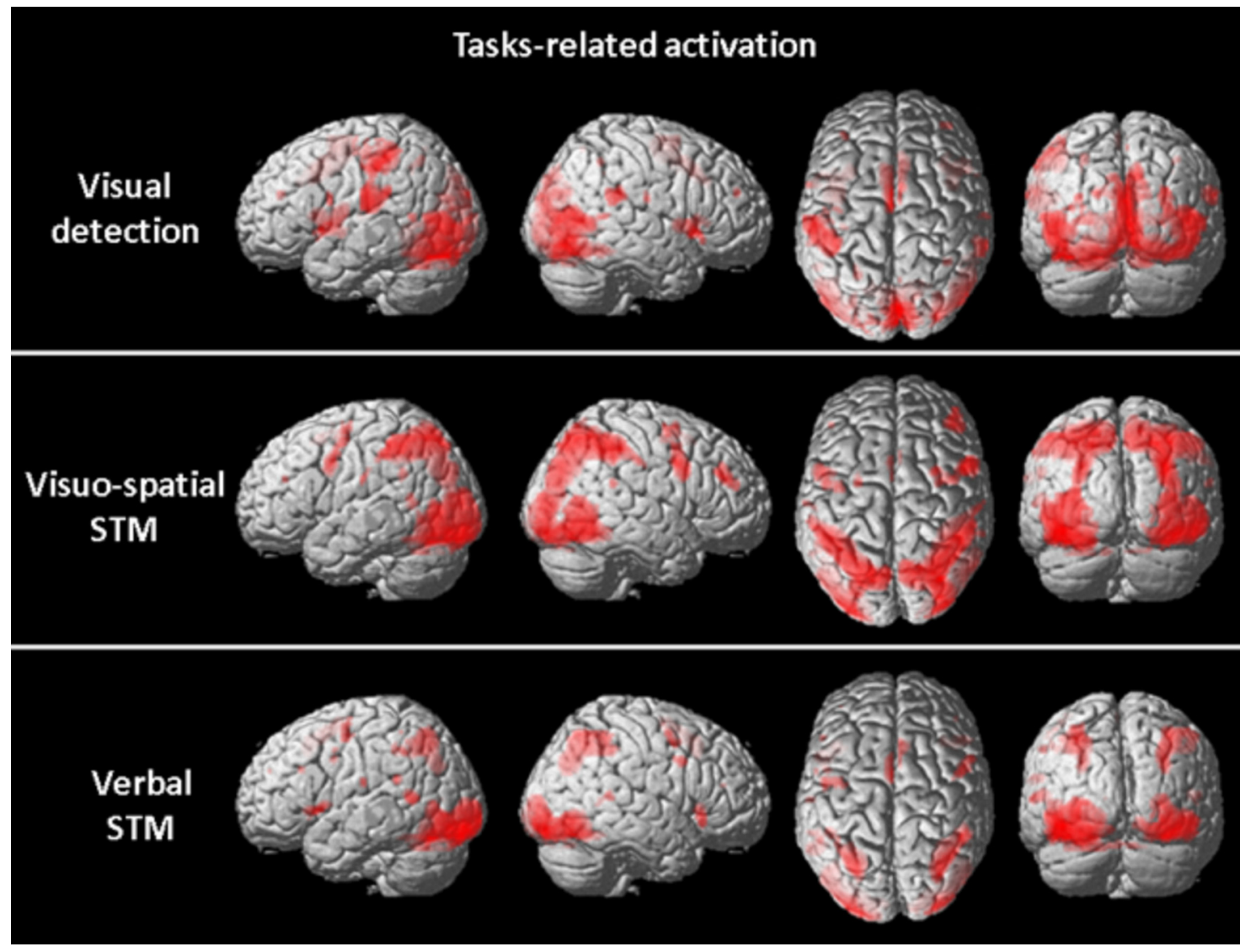

Figure 1. Surface renderings of average brain activation of both groups together for each task during the previsuomotor adaptation session ( $t$ tests; $p<0.001$, Family wise error (FWE) corrected).

normalized to the MNI template using a 12 parameter affine transformation. Finally, they were resliced to obtain a $2 \times 2 \times 2 \mathrm{~mm}$ voxel size and spatially smoothed using an isotropic Gaussian kernel of $6 \mathrm{~mm}$ FWHM to increase signal-to-noise ration.

First-level statistics were performed for each participant using the General Linear Model as implemented in SPM8 software (http://www. fil.ion.ucl.ac.uk/spm/software/spm8/). For each participant, the realignment parameters were included in the model as regressors. Contrasts of interests were specified for both sessions and for the three tasks in the same design. Maps from these contrasts were then used as input values for the second-level (group-level) statistics based on the random field theory. Group analysis was restricted to voxels with the probability of belonging to gray matter $>50 \%$, as defined in the a priori template available in SPM.

Statistical analyses on the activation maps were conducted on a general mixed-design ANOVA that included the factors group (PA, Ctl) as betweensubjects factor and task (visual detection, visuospatial STM, verbal STM) and session (Session 1, Session 2) as within-subjects factors. Starting from this ANOVA, the first statistical analyses were conducted on the task-related effects. These initial analyses involved the activation maps for the first session (i.e., before the intervention) for both groups together ( $t$ tests thresholded at $p<0.001$ with a Family wise error (FWE) correction).

From this general ANOVA, further analyses aimed to determine the effect of the intervention by analyzing first the interaction between our three factors (Group $\times$ Task $\times$ Session) and then for each task separately the interactions between the factors group and session. The generated statistical maps of activation for these interaction were thresholded at $p<0.05$ and cluster extent of $k>120$ (above the expected number of voxel per cluster). To further determine more precisely the effect of the intervention, analyses derived from the general ANOVA allowed to compare directly the Session 1 to the Session 2 for each task and each group. $t$ tests comparing both sessions were conducted for each task and each group. The generated statistical maps of activation for these $t$ tests were thresholded at $p<0.05$ and cluster extent of $k>50$ (above the expected number of voxel per cluster).

Furthermore, for the PA group, we analyzed the effect of the visuomotor adaptation on the activation related to the left, center, and right stimuli during the visual detection task. For this analysis, we used an ANOVA, including the factors stimulus locations (left, center, right) and session (Session 1, Session 2) to determine at first the global effect of 


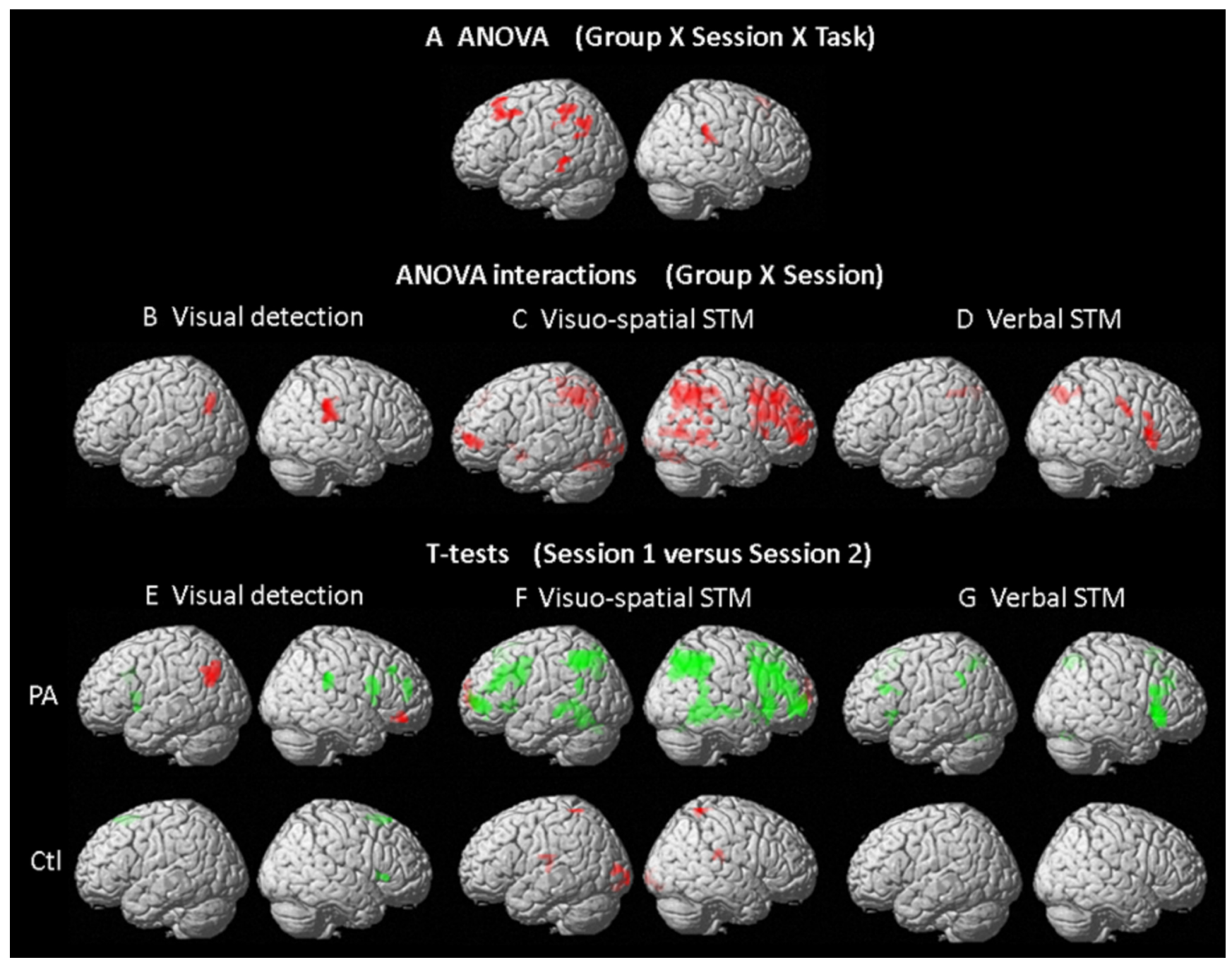

Figure 2. Surface renderings of the brain activation showing significant interaction in the mixed-design ANOVA with group as between-subject factor and task and session as within-subject factors. $\boldsymbol{A}$, Significant interaction between the three factors. $\boldsymbol{B}-\boldsymbol{D}$, Significant interaction between the factors group and session for the visual detection task ( $\boldsymbol{B})$, the visuospatial STM task $(\boldsymbol{C})$, and the verbal STM task (D). Significant differences between Session 1 and Session 2 ( $t$ test; red represents Session $2>$ Session 1; green represents Session $2<$ Session 1 ) are shown separately for the visual detection $(\boldsymbol{E})$, visuospatial STM $(\boldsymbol{F})$, and verbal STM tasks $(\boldsymbol{G})$. All maps are thresholded at $p<0.05$ and cluster extent of $k>120$ for the interactions, and $k>50$ for the $t$ tests. Ctl, Control group with plain glasses.

visuomotor adaptation during the detection task, and then the effect of the session ( $t$ tests, Session 1 vs Session 2 ) for each stimulus location. The generated statistical maps of activation for all of these analyses were thresholded at $p<0.01$ and cluster extent of $k>50$ (above the expected number of voxel per cluster). Finally, to analyze more precisely the direction of the prismatic adaptation's effect, ROI analyses were conducted using 3-mm-diameter spheres located on the peak of the left and right parietal regions showing a significant main effect of the session. Measures of the percentage signal changes in these ROIs were analyzed using $t$ tests comparing the activation before and after PA's exposure for the left, center, and right condition (using a Bonferroni correction $p=0.0167$ (0.05 divided by 3 ) for each ROI).

\section{Results}

Aftereffects of the visuomotor adaptation

Across subjects, the pointing error that occurred after the removal of the prismatic goggles was $66 \pm 16 \mathrm{~mm}$ (mean \pm SD) to the left of the left target and $56 \pm 19 \mathrm{~mm}$ to the left of the right target for the PA group. For the Ctl group, the pointing error was $7 \pm 11 \mathrm{~mm}$ to the left of the left target and $6 \pm 8 \mathrm{~mm}$ to the left of the right target. A two-way mixed-design ANOVA with group (PA, Ctl) as between-subjects factor and side of target (left, right) as within-subjects factor revealed a significant main effect of group $\left(F_{(1,25)}=148.6, p<0.0001\right)$ but no significant effect for the side of the target or the interaction. The aftereffects were globally larger for the PA than for the Ctl group.

\section{Behavioral results}

The three tasks (visual detection, visuospatial STM, and verbal STM) were readily performed by subjects (Table 1 ). The performance was analyzed with a three-way mixed-design ANOVA with group (PA, Ctl) as between-subjects factor, task (visual detection, visuospatial STM, verbal STM) and session (preintervention, postintervention) as two-level within-subjects factor. For accuracy, there was neither significant main effect nor significant interactions. For response times, the main effect of task was significant $\left(F_{(2,25)}=248,00 ; p=1.7 \times 10^{-14}\right)$, but neither main effects of group or session nor any of the interactions were significant. Post hoc analysis revealed that response times were significantly shorter for visual detection than for visuospatial STM $(t=$ $\left.10.17 ; p=9.8 \times 10^{-11}\right)$ or for verbal STM $(t=15.94 ; p=2.9 \times$ $\left.10^{-15}\right)$ and shorter for spatial STM than verbal STM $(t=6.47$; $\left.p=6.4 \times 10^{-7}\right)$. 
Table 2. Brain regions showing significant effects in the three-way ANOVA (Group $\times$ Task $\times$ Session) and in the two-way ANOVA for each task (Group $\times$ Session) ${ }^{a}$

\begin{tabular}{|c|c|c|c|c|}
\hline Area & BA & No. of voxels & Peak intensity & Peak MNI coordinates \\
\hline \multicolumn{5}{|l|}{ Three-way ANOVA (Group $\times$ Session $\times$ Task) } \\
\hline Left middle temporal gyrus & 21 & 125 & 6.25 & $-64,-42,0$ \\
\hline Right supramarginal gyrus & 40 & 195 & 6.04 & $42,-30,24$ \\
\hline Left superior and middle frontal gyri & 6,8 & 163 & 6.02 & $-18,22,62$ \\
\hline Left inferior parietal lobule & 40 & 179 & 5.73 & $-52,-48,52$ \\
\hline Left middle frontal and precentral gyri & 8,6 & 239 & 5.32 & $-36,8,48$ \\
\hline Left angular and supramarginal gyri & 39,40 & 190 & 5.11 & $-54,-60,38$ \\
\hline \multicolumn{5}{|l|}{ Visual detection task (Group $\times$ Session) } \\
\hline Right supramarginal gyrus, inferior parietal lobule & 40 & 542 & 15.02 & $44,-30,26$ \\
\hline Left angular gyrus, inferior parietal lobule & 39,40 & 153 & 7.96 & $-46,-66,32$ \\
\hline \multicolumn{5}{|l|}{ Visuospatial STM task (Group × Session) } \\
\hline Left middle and inferior frontal gyri & $10,46,47$ & 411 & 17.85 & $-28,52,-2$ \\
\hline Right middle, inferior frontal, and superior frontal gyri & $6,8,9,10,44,45,46$ & 3729 & 14.54 & $52,10,42$ \\
\hline Left and right cerebellum & & 766 & 14.42 & $-12,-70,-26$ \\
\hline Right middle cingulate gyrus, precuneus & 31,23 & 383 & 14.01 & $14,-44,34$ \\
\hline Right inferior parietal lobule, preucuneus, angular gyrus, middle and superior temporal gyri & $7,19,21,22,37,39,40$ & 3563 & 13.23 & $16,-72,44$ \\
\hline Left superior and inferior parietal lobules, precuneus, angular gyrus & $7,39,40$ & 1306 & 12.71 & $-28,-58,44$ \\
\hline Left insula, superior temporal gyrus, putamen & 13,22 & 140 & 12.71 & $-28,4,-16$ \\
\hline Right superior parietal lobule & 7 & 148 & 7.22 & $18,-52,68$ \\
\hline Left lingual gyrus, cuneus & 17,18 & 128 & 6.98 & $-4,-84,-10$ \\
\hline Left middle occipital gyrus & 18 & 126 & 6.21 & $-34,-86,0$ \\
\hline \multicolumn{5}{|l|}{ Verbal STM task (Group $\times$ Session) } \\
\hline Right inferior frontal gyrus, insula & $45,44,47,13$ & 640 & 12.29 & $52,20,6$ \\
\hline Right postcentral and precentral gyri & 6,4 & 217 & 10.80 & $50,-4,30$ \\
\hline Right precuneus, superior occipital and superior parietal gyri & $7,19,40$ & 605 & 8.78 & $30,-66,42$ \\
\hline Left inferior and superior parietal lobule & 7,40 & 133 & 7.60 & $-28,-58,46$ \\
\hline
\end{tabular}

${ }^{a} \mathrm{BA}$, Brodmann area; MNI, Montreal Neurological Institute.

\section{Task-related activation}

Task-related activation patterns were assessed by exploring activity during each of the tasks in the preintervention session in both groups together (Fig. 1). Visual detection activated bilaterally the occipital cortex and the frontal operculum, the left precentral cortex, and the right parieto-occipital junction. Visuospatial STM activated bilaterally occipitoparietal, precentral, and prefrontal cortex. Verbal STM activated bilaterally occipitoparietal, prefrontal, and precentral cortex. Activation in the left superior motor areas is observed in each task and is related to participant's response with the right hand.

\section{Intervention-related changes in activation patterns}

Intervention-related changes in activation patterns were analyzed with a mixed-design ANOVA with group (PA, Ctl) as between-subjects factor, and task (visual detection, visuospatial STM, verbal STM) and session (Session 1, Session 2) as withinsubjects factors. First, the analysis of the triple interaction of this ANOVA (Fig. 2A) was conducted to determine the global effect of the intervention while taken into account the effects of the tasks and the groups. Significant interaction (Table 2) was found bilaterally in the inferior parietal lobule, corresponding mainly to the angular gyrus and posterior part of the supramarginal gyrus on the left side and to the supramarginal gyrus on the right side. Additional interaction is also significant in the left middle temporal gyrus and bilaterally in frontal areas.

Intervention-related changes in these parietal regions were further analyzed from the general ANOVA by examining the interaction between the factors group and session for each task separately (Fig. $2 B-D$; Table 2). This interaction for the visual detection task was significant in the right supramarginal gyrus and left angular gyrus. $t$ tests comparing the activation before and after the intervention for each group separately (Fig. 2E) showed that the parietal interactions were the result of a modulation observed in the PA group and not in the control group. Moreover, the activation in the left angular gyrus is related to an increase of activation after the intervention, whereas the activation in the right supramarginal gyrus is the result of to a decrease of activation after the intervention. The same analyses were performed for the visuospatial STM task and showed large interactions bilaterally in the middle and inferior frontal gyri, the inferior and superior parietal lobules, occipital cortex, and the cerebellum (Fig. 2C; Table 2). As determined by the $t$ tests (Fig. $2 F)$, most of these interactions were the result of the decrease of activation after the intervention in the PA group. For the verbal STM task, similar effects (Fig. 2D, G; Table 2) were observed but to a smaller extent.

\section{Changes in visual field representations}

Our previous analyses showed that PA intervention had a specific effect on the involvement of parietal regions in visual detection. We further investigated whether PA affects differentially the representations of the left, central, and right visual field using a twoway ANOVA with session (Session 1, Session 2) and stimulus position (left, center, right) as within-subject factors. The main effect of session was significant in the left angular gyrus and the right supramarginal gyrus, as well as in frontal, cingulated, and insular regions (Fig. 3A; Table 3). In a post hoc analysis, Session 1 and Session 2 were compared separately for left, center, and right stimuli (Fig. $3 B-D$ ). For left stimuli, PA yielded an increase in activation in the left angular gyrus and in small regions of the prefrontal convexity as well as in several small clusters in the right temporal, parietal, and prefrontal cortices (Fig. $3 B$ ). For central stimuli, PA yielded an increase in activation in the left angular gyrus and in a small cluster in the right inferior frontal gyrus, and a decrease in the right supramarginal gyrus and right parietal operculum (Fig. 3C). For right stimuli, PA yielded an increase in activation in the left angular gyrus and a decrease in the right 

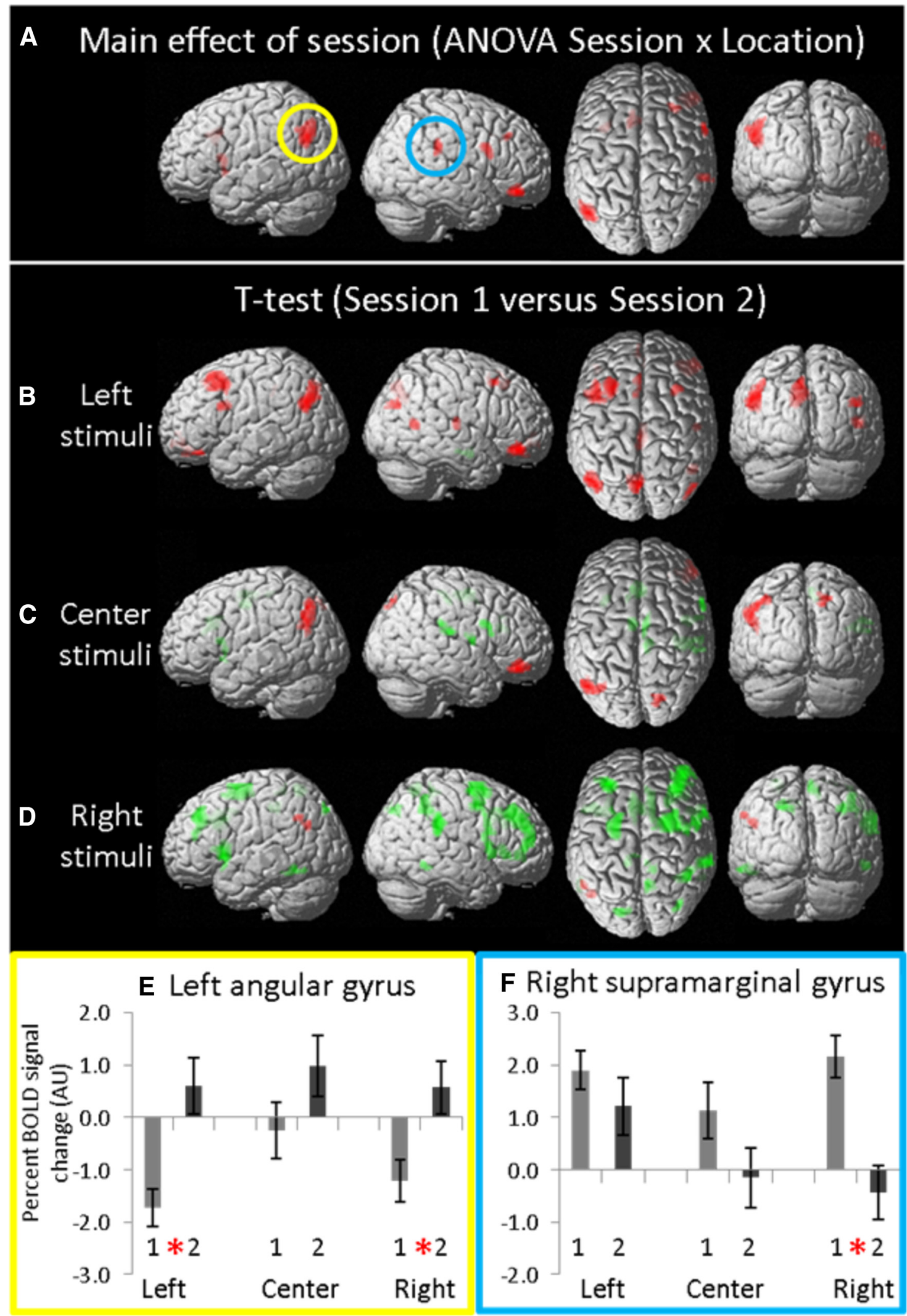

Figure 3. Visual detection task in the PA group. $A$, Surface renderings of brain activation showing significant main effect of the factor session in the two-way ANOVA (Session $\times$ Stimulus location). $\boldsymbol{B}-\boldsymbol{D}$, Surface renderings of significant changes post- versus pre-PA ( $t$ tests) for left, center, and right stimuli, respectively. Red represents Session $2>$ Session 1 ; green represents Session $2<$ Session 1. $E, F$, Graphs (mean and SEM) of the percentage BOLD signal changes in Session 1 and Session 2 in the left angular and right supramarginal gyri (outlined in $\boldsymbol{A}$ in yellow and blue, respectively) as function of the position of the visual stimuli. *Significant difference between Session 1 and Session 2 ( $t$ tests, $p=0.0167$ ( 0.05 divided by 3 ) with a Bonferroni correction for each R0I). All maps are thresholded at $p<0.01$ and cluster extent of $k>50$. AU, Arbitrary unit. 
Table 3. Brain regions showing significant main effect of the session in the two-way ANOVA (Session $\times$ Location) during the visual detection task in the PA group

\begin{tabular}{|c|c|c|c|c|}
\hline Area & $\mathrm{BA}$ & No. of voxels & Peak intensity & Peak MNI coordinates \\
\hline Left middle cingulate gyrus, anterior cingulate gyrus & 24,32 & 112 & 19.85 & $-10,14,32$ \\
\hline Left angular gyrus, supramarginal gyrus, inferior parietal lobule & 39,40 & 322 & 19.48 & $-46,-66,30$ \\
\hline Right inferior frontal gyrus & 47 & 163 & 18.58 & $48,38,-14$ \\
\hline Right inferior frontal gyrus & 44 & 71 & 14.01 & $60,10,26$ \\
\hline Left insula & 13 & 108 & 13.87 & $-30,14,12$ \\
\hline Right supramarginal gyrus, inferior parietal lobule & 40 & 100 & 11.63 & $60,-34,28$ \\
\hline Right middle frontal gyrus & 9 & 47 & 10.41 & $32,30,38$ \\
\hline
\end{tabular}

supramarginal gyrus and bilaterally in several regions of the prefrontal and temporal cortices (Fig. 3D). Percentage BOLD signal changes were analyzed in ROIs located on the peak of the significant main effect of session in the ANOVA Session $X$ Location in the left angular and right supramarginal gyri (Fig. 3 E, F, outlined in yellow and blue, respectively). They showed an increase in activation after PA intervention in the left angular gyrus for the all stimuli, and a decrease in the right supramarginal gyrus for the right and central stimuli. These observations suggest that PA (1) enhances the involvement of the left angular gyrus in visual field representations and (2) decreases the involvement of the right supramarginal gyrus in the representation of the ipsilateral and central stimuli.

\section{Discussion}

Our results demonstrated that a brief PA exposure using rightward deviating prisms changes how the parietal cortex processes subsequent stimuli. This modulation is task-specific: left and right parietal regions were modulated differentially for visual detection, in the same way for visuospatial STM, and almost not at all for verbal STM. In the visual detection task, PA enhanced the involvement of the left angular gyrus in the entire visual field representations and decreased the involvement of the right supramarginal gyrus in the representation of the right and central stimuli. One widely accepted view is that the right hemisphere is involved in shifts of attention for left and right hemifields, whereas the left hemisphere is involved for shifts of attention in the right hemifield (Mesulam, 1981). Several studies (for reviews, see Corbetta and Shulman, 2002; Corbetta et al., 2005) have confirmed that the right hemisphere is more active than the left hemisphere in tasks requiring visuospatial and/or attentionnal processing, such as our visual detection task. In our task, the increase in the left hemisphere and decrease in the right hemisphere can therefore be interpreted as a reversal of the right hemispheric dominance for such processing. Further studies focusing on PA-related modulation in parietal regions during visuospatial processing should be conducted to confirm this interpretation.

Before discussing the implications of these results, we would like to raise several methodological issues. First, the brief exposure to PA caused an aftereffect that lasted beyond the three tasks executed during the post-PA fMRI session. This persistence is in agreement with previous reports of the persistence for $\geq 24 \mathrm{~h}$ of behavioral effects after PA using leftward deviating prisms (Hatada et al., 2006a). In a recent study, Schintu et al. (2014) have also shown behavioral effects after PA that were stable $40 \mathrm{~min}$ after the adaptation when leftward but also rightward deviating prisms were used. Second, we were careful to decrease the impact of the between-group design, by matching number of subjects as well as their gender and age. The same design was used in the two groups, including pointing to targets; the only difference between the groups was the use of prisms. We have opted against a single group study because of the potentially large test-retest effects on the tasks. Third, one could argue that pointing toward the targets during the control experiment (without prisms) may be relatively boring and introduce thus an additional difference between the PA and control condition. As in previous reports (e.g., Luauté et al., 2009), all subjects in the PA group corrected their pointing very rapidly, reducing the challenging adaptation part to the initial 5-10 trials; the remaining 140 trials were performed without any effort, very similarly to the $\sim 150$ pointing trials in the control group. Fourth, the simple visual detection task, rather than the cued attentional orienting (Posner, 1980), was chosen here because it is relatively brief and the paradigm can be easily transferred to fMRI studies with neglect patients. The differential influences of PA on reflexive and voluntary covert attention, which was demonstrated behaviorally in previous studies (Striemer et al., 2006; Striemer and Danckert, 2007), should be explored in further studies.

\section{Parietal involvement in PA}

The involvement of the parietal cortex in different aspects of PA has been demonstrated in a series of previous studies (Clower et al., 1996; Danckert et al., 2008; Luauté et al., 2009; Chapman et al., 2010). The exposure to alternating left versus right deviating prisms yielded an increased activation within the lateral bank of the intraparietal sulcus contralateral to the hand that was pointing, suggesting a role of this region in aligning the visual and proprioceptive representations of hand position (Clower et al., 1996). A later study used rightward prisms and contrasted early versus late trials of pointing under PA; the higher neural activity in the left primary motor area, the anterior cingulate cortex, the anterior part of the left intraparietal cortex and the vermis was interpreted in the context of recalibration of visuomotor commands (Danckert et al., 2008). Two further studies used leftward prisms. By comparing neural activity associated with pointing during preexposure baseline, early, and late phases of PA, and the aftereffect, Luaute et al. (2009) identified the specific contributions of the key regions as error detection for the left and right intraparietal sulci; error correction for the left parieto-occipital sulcus; and the progressively developing compensation of prismatic effects for the right and left superior temporal gyri and sulci. By analyzing early and late pointing trials under PA, Chapman et al. (2010) identified regions involved in error correction (left and right cerebellum, right superior parietal lobule, and right inferior parietal lobule) and those involved in spatial realignment (left and right cerebellum, right superior parietal lobule, the anterior part of the right inferior parietal lobule, and the right angular gyrus); contrasting spatial realignment versus error correction during pointing trials revealed greater neural activity in the right cerebellum, the right angular gyrus, and the anterior part of the right inferior parietal lobule. Together, the four studies highlight the role of the intraparietal sulcus in the transformation of the visuomotor coordinates. 
Current evidence points out that the posterior parietal cortex contains two distinct sets of visual space representations. The intraparietal sulcus was proposed to form together with the frontal eye field the dorsal attentional network, which controls the endogenous allocation and maintenance of visuospatial attention (Corbetta and Shulman, 2002). A separate, right ventral hemispheric network involving the temporoparietal junction was shown to sustain visual target detection independently of the hemifield and to carry left and right hemifield representation (Corbetta and Shulman, 2002; Thiel et al., 2004; Shulman et al., 2010). The comparison of our data with these studies strongly suggests that PA exposure affects neural processing within the right-lateralized inferior parietal network centered on the inferior parietal lobule, which governs shifts of spatial attention and target detection, and not within the dorsal frontoparietal network, which controls the allocation of endogenous attention (Shulman et al., 2010).

\section{Mechanisms underlying PA-related effects}

The neural mechanisms by which PA changes visuospatial representations within the inferior parietal lobule are partially understood. Our study clarifies three issues. First, PA does not alter in a similar way all types of visuospatial processing, in particular PA induced a general decreased of activation in regions involved in visuospatial STM task (Awh et al., 1995; Courtney et al., 1998; Corbetta et al., 2002; Crottaz-Herbette et al., 2004; Chang et al., 2007; Sala and Courtney, 2007; Ackerman and Courtney, 2012). Second, the effect of PA on visuospatial representations within the inferior parietal lobule cannot be simply explained by a leftward shift, as observed in the afteraffect. The right, but not the left, inferior parietal lobule is known to carry left and right hemifield representation (Corbetta and Shulman, 2002; Thiel et al., 2004; Shulman et al., 2010) and to have a strong functional interaction with retinotopic visual areas in either hemisphere (Ruff et al., 2008). A leftward shift may bring the representation of right stimulus within the left (representational) space but cannot be expected to change the competence of the right inferior parietal lobule for both the right and left space. Third, the most parsimonious explanation of the changes in visuospatial representations within the inferior parietal lobule is that PA induces a reversal of right hemispheric dominance for visual space. The rapidity of the change suggests that it occurs by uncovering preexisting ipsilateral field representations within the left parietal cortex. It is striking that the change in neural substrate was not associated with any significant change in performance accuracy or rapidity.

\section{PA in neglect}

PA-induced changes in the lateralization of the ventral attentional system, associated with the recruitment of the left inferior parietal lobule, which we have demonstrated here in normal subjects, may underlie the therapeutic effect of PA in neglect, which was reported in several studies (Rossetti et al., 1998; Rode et al., 2006). Such an interpretation is compatible with two lines of evidence from previous neglect studies. First, positive effects of PA in neglect are associated with increased left or bilateral involvement as described in two studies. PA-induced improvement of neglect symptoms was found to correlate with increase blood flow within left temporo-occipital and subcortical regions (Luauté et al., 2006). Exposure to PA was shown to increase neural activity during line bisection and visual search tasks bilaterally on the occipito-parieto-frontal convexity (Saj et al., 2013). Second, the left inferior parietal lobule is critical for successful visuomo- tor adaptation to occur, including its aftereffects (Mutha et al., 2011).

Neglect patients present sometimes deficits in spatial working memory (Parton et al., 2004; Malhotra et al., 2005; Danckert and Ferber, 2006), which appear to be resistant to PA therapy (Striemer et al., 2013). Our observation that PA does not have a similar effect on the neural processing underlying visual detection and STM offers only a partial explanation to the lack of efficacy of PA therapy for working memory deficits in neglect patients. Further studies should be conducted on neglect patients to clarify this point.

\section{References}

Ackerman CM, Courtney SM (2012) Spatial relations and spatial locations are dissociated within prefrontal and parietal cortex. J Neurophysiol 108: 2419-2429. CrossRef Medline

Awh E, Smith EE, Jonides J (1995) Human rehearsal processes and the frontal lobes: PET evidence. Ann N Y Acad Sci 769:97-117. CrossRef Medline

Berberovic N, Mattingley JB (2003) Effects of prismatic adaptation on judgements of spatial extent in peripersonal and extrapersonal space. Neuropsychologia 41:493-503. CrossRef Medline

Bultitude JH, Van der Stigchel S, Nijboer TC (2013) Prism adaptation alters spatial remapping in healthy individuals: evidence from double-step saccades. Cortex 49:759-770. CrossRef Medline

Chang C, Crottaz-Herbette S, Menon V (2007) Temporal dynamics of basal ganglia response and connectivity during verbal working memory. Neuroimage 34:1253-1269. CrossRef Medline

Chapman HL, Eramudugolla R, Gavrilescu M, Strudwick MW, Loftus A, Cunnington R, Mattingley JB (2010) Neural mechanisms underlying spatial realignment during adaptation to optical wedge prisms. Neuropsychologia 48:2595-2601. CrossRef Medline

Clower DM, Hoffman JM, Votaw JR, Faber TL, Woods RP, Alexander GE (1996) Role of posterior parietal cortex in the recalibration of visually guided reaching. Nature 383:618-621. CrossRef Medline

Colent C, Pisella L, Bernieri C, Rode G, Rossetti Y (2000) Cognitive bias induced by visuo-motor adaptation to prisms: a simulation of unilateral neglect in normal individuals? Neuroreport 11:1899-1902. CrossRef Medline

Corbetta M, Shulman GL (2002) Control of goal-directed and stimulusdriven attention in the brain. Nat Rev Neurosci 3:201-215. CrossRef Medline

Corbetta M, Kincade JM, Shulman GL (2002) Neural systems for visual orienting and their relationships to spatial working memory. J Cogn Neurosci 14:508-523. CrossRef Medline

Corbetta M, Kincade MJ, Lewis C, Snyder AZ, Sapir A (2005) Neural basis and recovery of spatial attention deficits in spatial neglect. Nat Neurosci 8:1603-1610. CrossRef Medline

Courtney SM, Petit L, Maisog JM, Ungerleider LG, Haxby JV (1998) An area specialized for spatial working memory in human frontal cortex. Science 279:1347-1351. CrossRef Medline

Crottaz-Herbette S, Anagnoson RT, Menon V (2004) Modality effects in verbal working memory: differential prefrontal and parietal responses to auditory and visual stimuli. Neuroimage 21:340-351. CrossRef Medline

Danckert J, Ferber S (2006) Revisiting unilateral neglect. Neuropsychologia 44:987-1006. CrossRef Medline

Danckert J, Ferber S, Goodale MA (2008) Direct effects of prismatic lenses on visuomotor control: an event-related functional MRI study. Eur J Neurosci 28:1696-1704. CrossRef Medline

Diedrichsen J, Hashambhoy Y, Rane T, Shadmehr R (2005) Neural correlates of reach errors. J Neurosci 25:9919-9931. CrossRef Medline

Dijkerman HC, McIntosh RD, Milner AD, Rossetti Y, Tilikete C, Roberts RC (2003) Ocular scanning and perceptual size distortion in hemispatial neglect: effects of prism adaptation and sequential stimulus presentation. Exp Brain Res 153:220-230. CrossRef Medline

Ferber S, Danckert J, Joanisse M, Goltz HC, Goodale MA (2003) Eye movements tell only half the story. Neurology 60:1826-1829. CrossRef Medline

Girardi M, McIntosh RD, Michel C, Vallar G, Rossetti Y (2004) Sensorimotor effects on central space representation: prism adaptation influences haptic and visual representations in normal subjects. Neuropsychologia 42:1477-1487. CrossRef Medline 
Graydon FX, Friston KJ, Thomas CG, Brooks VB, Menon RS (2005) Learning-related fMRI activation associated with a rotational visuomotor transformation. Brain Res Cogn Brain Res 22:373-383. CrossRef Medline

Grefkes C, Ritzl A, Zilles K, Fink GR (2004) Human medial intraparietal cortex subserves visuomotor coordinate transformation. Neuroimage 23: 1494-1506. CrossRef Medline

Hatada Y, Miall RC, Rossetti Y (2006a) Two waves of a long-lasting aftereffect of prism adaptation measured over 7 days. Exp Brain Res 169:417426. CrossRef Medline

Hatada Y, Rossetti Y, Miall RC (2006b) Long-lasting aftereffect of a single prism adaptation: shifts in vision and proprioception are independent. Exp Brain Res 173:415-424. CrossRef Medline

Inoue K, Kawashima R, Satoh K, Kinomura S, Sugiura M, Goto R, Ito M, Fukuda H (2000) A PET study of visuomotor learning under optical rotation. Neuroimage 11:505-516. CrossRef Medline

Jacquin-Courtois S, Rode G, Pavani F, O'Shea J, Giard MH, Boisson D, Rossetti Y (2010) Effect of prism adaptation on left dichotic listening deficit in neglect patients: glasses to hear better? Brain 133:895-908. CrossRef Medline

Jacquin-Courtois S, O’Shea J, Luauté J, Pisella L, Revol P, Mizuno K, Rode G, Rossetti Y (2013) Rehabilitation of spatial neglect by prism adaptation: a peculiar expansion of sensorimotor after-effects to spatial cognition. Neurosci Biobehav Rev 37:594-609. CrossRef Medline

Krakauer JW, Ghilardi MF, Mentis M, Barnes A, Veytsman M, Eidelberg D, Ghez C (2004) Differential cortical and subcortical activations in learning rotations and gains for reaching: a PET study. J Neurophysiol 91:924933. CrossRef Medline

Loftus AM, Nicholls ME, Mattingley JB, Bradshaw JL (2008) Left to right: representational biases for numbers and the effect of visuomotor adaptation. Cognition 107:1048-1058. CrossRef Medline

Luauté J, Michel C, Rode G, Pisella L, Jacquin-Courtois S, Costes N, Cotton F, le Bars D, Boisson D, Halligan P, Rosetti Y (2006) Functional anatomy of the therapeutic effects of prism adaptation on left neglect. Neurology 66:1859-1867. CrossRef Medline

Luauté J, Schwartz S, Rossetti Y, Spiridon M, Rode G, Boisson D, Vuilleumier P (2009) Dynamic changes in brain activity during prism adaptation. J Neurosci 29:169-178. CrossRef Medline

Malhotra P, Mannan S, Driver J, Husain M (2004) Impaired spatial working memory: one component of the visual neglect syndrome? Cortex 40:667676. CrossRef Medline

Malhotra P, Jäger HR, Parton A, Greenwood R, Playford ED, Brown MM, Driver J, Husain M (2005) Spatial working memory capacity in unilateral neglect. Brain 128:424-435. CrossRef Medline

Maravita A, McNeil J, Malhotra P, Greenwood R, Husain M, Driver J (2003) Prism adaptation can improve contralesional tactile perception in neglect. Neurology 60:1829-1831. CrossRef Medline

McIntosh RD, Rossetti Y, Milner AD (2002) Prism adaptation improves chronic visual and haptic neglect: a single case study. Cortex 38:309-320. CrossRef Medline

Mesulam MM (1981) A cortical network for directed attention and unilateral neglect. Ann Neurol 10:309-325. CrossRef Medline

Michel C, Pisella L, Halligan PW, Luauté J, Rode G, Boisson D, Rossetti Y (2003) Simulating unilateral neglect in normals using prism adaptation: implications for theory. Neuropsychologia 41:25-39. CrossRef Medline

Mutha PK, Sainburg RL, Haaland KY (2011) Left parietal regions are critical for adaptive visuomotor control. J Neurosci 31:6972-6981. CrossRef Medline

Nicholls ME, Kamer A, Loftus AM (2008) Pseudoneglect for mental alphabet lines is affected by prismatic adaptation. Exp Brain Res 191:109-115. CrossRef Medline

Oldfield RC (1971) The assessment and analysis of handedness: the Edinburgh inventory. Neuropsychologia 9:97-113. CrossRef Medline

Parton A, Malhotra P, Husain M (2004) Hemispatial neglect. J Neurol Neurosurg Psychiatry 75:13-21. Medline
Pisella L, Rode G, Farnè A, Tilikete C, Rossetti Y (2006) Prism adaptation in the rehabilitation of patients with visuo-spatial cognitive disorders. Curr Opin Neurol 19:534-542. CrossRef Medline

Posner MI (1980) Orienting of attention. QJ Exp Psychol 32:3-25. CrossRef Medline

Redding GM, Wallace B (1993) Adaptive coordination and alignment of eye and hand. J Mot Behav 25:75-88. CrossRef Medline

Redding GM, Rossetti Y, Wallace B (2005) Applications of prism adaptation: a tutorial in theory and method. Neurosci Biobehav Rev 29:431444. CrossRef Medline

Rode G, Rossetti Y, Boisson D (2001) Prism adaptation improves representational neglect. Neuropsychologia 39:1250-1254. CrossRef Medline

Rode G, Pisella L, Marsal L, Mercier S, Rossetti Y, Boisson D (2006) Prism adaptation improves spatial dysgraphia following right brain damage. Neuropsychologia 44:2487-2493. CrossRef Medline

Rossetti Y, Rode G, Pisella L, Farné A, Li L, Boisson D, Perenin MT (1998) Prism adaptation to a rightward optical deviation rehabilitates left hemispatial neglect. Nature 395:166-169. CrossRef Medline

Ruff CC, Bestmann S, Blankenburg F, Bjoertomt O, Josephs O, Weiskopf N, Deichmann R, Driver J (2008) Distinct causal influences of parietal versus frontal areas on human visual cortex: evidence from concurrent TMSfMRI. Cereb Cortex 18:817-827. CrossRef Medline

Saj A, Cojan Y, Vocat R, Luauté J, Vuilleumier P (2013) Prism adaptation enhances activity of intact parietal areas in both hemispheres in neglect patients. Cortex 49:107-119. CrossRef Medline

Sala JB, Courtney SM (2007) Binding of what and where during working memory maintenance. Cortex 43:5-21. CrossRef Medline

Sarri M, Kalra L, Greenwood R, Driver J (2006) Prism adaptation changes perceptual awareness for chimeric visual objects but not for chimeric faces in spatial neglect after right-hemisphere stroke. Neurocase 12:127-135. CrossRef Medline

Sarri M, Greenwood R, Kalra L, Papps B, Husain M, Driver J (2008) Prism adaptation aftereffects in stroke patients with spatial neglect: pathological effects on subjective straight ahead but not visual open-loop pointing. Neuropsychologia 46:1069-1080. CrossRef Medline

Sarri M, Greenwood R, Kalra L, Driver J (2011) Prism adaptation does not change the rightward spatial preference bias found with ambiguous stimuli in unilateral neglect. Cortex 47:353-366. CrossRef Medline

Schintu S, Pisella L, Jacobs S, Salemme R, Reilly KT, Farnè A (2014) Prism adaptation in the healthy brain: the shift in line bisection judgments is long lasting and fluctuates. Neuropsychologia 53:165-170. CrossRef Medline

Shulman GL, Pope DL, Astafiev SV, McAvoy MP, Snyder AZ, Corbetta M (2010) Right hemisphere dominance during spatial selective attention and target detection occurs outside the dorsal frontoparietal network. J Neurosci 30:3640-3651. CrossRef Medline

Striemer C, Danckert J (2007) Prism adaptation reduces the disengage deficit in right brain damage patients. Neuroreport 18:99-103. CrossRef Medline

Striemer CL, Ferber S, Danckert J (2013) Spatial working memory deficits represent a core challenge for rehabilitating neglect. Front Hum Neurosci 7:334-345. CrossRef Medline

Striemer C, Sablatnig J, Danckert J (2006) Differential influences of prism adaptation on reflexive and voluntary covert attention. J Int Neuropsychol Soc 12:337-349. Medline

Thiel CM, Zilles K, Fink GR (2004) Cerebral correlates of alerting, orienting and reorienting of visuospatial attention: an event-related fMRI study. Neuroimage 21:318-328. CrossRef Medline

Tilikete C, Rode G, Rossetti Y, Pichon J, Li L, Boisson D (2001) Prism adaptation to rightward optical deviation improves postural imbalance in left-hemiparetic patients. Curr Biol 11:524-528. CrossRef Medline

Weiner MJ, Hallett M, Funkenstein HH (1983) Adaptation to lateral displacement of vision in patients with lesions of the central nervous system. Neurology 33:766-772. CrossRef Medline 